\title{
Improving projections of rainfall trends through regional climate modeling and wide-ranging assessment
}

\author{
$\underline{\text { M.R Grose }}^{\text {a }}$, S.P Corney ${ }^{\text {a }}$, J.J. Katzfey ${ }^{\text {b }}$, J.C Bennett ${ }^{\mathrm{cd}}$ and N.L Bindoff ${ }^{\text {a b c }}$ \\ ${ }^{a}$ Antarctic Climate and Ecosystems Cooperative Research Centre (ACE CRC) \\ ${ }^{b}$ CSIRO Marine and Atmospheric Research (CMAR) \\ ${ }^{c}$ Institute of Marine and Antarctic Science (IMAS) \\ ${ }^{d}$ Entura \\ Email: michael.grose@utas.edu.au
}

\begin{abstract}
General Circulation Models (GCMs) are our best tool for assessing potential changes to our climate on a global scale into the future. However, certain physical processes that influence rainfall at any particular location operate at finer spatial scales than can be simulated by GCMs. Dynamical downscaling using regional climate models (RCMs) addresses this problem by simulating the relevant processes at finer scales, whilst retaining the important large-scale features of the original GCM. Assessment of the RCM simulations is an essential task before using them as a guide for potential future rainfall trends. Assessing the outputs of models both in terms of their simulation of relevant output variables (e.g. rainfall) and also the dynamics gives a more comprehensive assessment than examining the variables alone. Similarly, understanding the dynamics driving the projected trends from the model simulation can be used to gauge the plausibility of that projected trend.
\end{abstract}

Here we present dynamically downscaled simulations of rainfall over the study site of Tasmania, Australia ( $\sim 10 \mathrm{~km}$ grid scale). These fine-scale projections were produced using a dynamical downscaling regional climate model. Rainfall in the simulations is validated against a gridded climate dataset based on observations, and the model simulation of broad climate fields such as mean pressure and wind fields were assessed by comparison to reanalysis datasets. Additionally, the projected rainfall trends are interpreted in terms of known climate drivers.

While GCM projections to 2100 show fairly uniform rainfall trends over all of Tasmania, the RCM projections reveal distinct trends in the different districts of Tasmania. The spatial pattern of rainfall changes also varies greatly in each season. The change in each district is driven by a unique combination of drivers and processes. The main climate drivers of change include the alteration to mean circulation in response to surface warming, changes to the strength and position of the subtropical ridge, shifts in atmospheric blocking, the southern annular mode, as well as changes to the synoptic climatology of significant systems. At a scale relevant to Tasmania the climate response to these processes is often poorly resolved in GCM simulations, and is improved through regional modelling. In this paper we present a holistic view of rainfall changes over Tasmania, linking large-scale drivers and finer scale processes to spatial and temporal changes in rainfall. Such analyses are only possible with fine-scale dynamical downscaling. We conclude that including new information from increased resolution using fine-scale dynamical downscaling provides more useful projections of rainfall changes at a local scale. We propose that analysis of the relevant rainfall mechanisms also helps to assess the confidence in which the climate simulations should be used as a tool for understanding future changes in rainfall.

Keywords: Regional climate modeling (RCM), Downscaling, Climate change, Rainfall trends 
Grose et al., Improving projections of rainfall trends through regional climate modelling and wide-ranging assessment

\section{INTRODUCTION}

\subsection{Climate modeling for the regional scale}

Global climate models (GCM) are the best tool for projecting likely changes to global patterns of rainfall with a warming climate. However, for rainfall trends at the continental or regional scale there is a spread between the models, a lack of model agreement and a lack of model consensus in the sign of change except for the strongest signals (Meehl et al. 2007). Furthermore, obtaining regional detail of projected rainfall trend is difficult from GCM-scale simulations. GCMs typically have horizontal resolutions of $>100 \mathrm{~km}$, meaning that they have a spatially-filtered representation of features such as topography. This means there is spatially limited simulation of orographic rainfall processes, the response to land-sea boundaries and synoptic-scale processes such as intense lows and fronts. GCMs also have broad parameterisations of convection, cloud and humidity.

Increased spatial resolution can enhance the simulation of rainfall processes at the regional scale and give a more detailed projection of rainfall trends. However, spatial resolution is not the only aspect of obtaining greater model skill and accuracy: model biases can remain through the imperfect representation of climate processes. There will always be fundamental inaccuracies in describing processes with continuous length and temporal scales using a discretised system. The theoretical, ideal climate model would have perfect representation of climate processes in the model, combined with virtually infinite horizontal and vertical resolution. However, the realisation of this ideal is limited by our knowledge of processes and how to represent them in models, as well as limitations of computing capacity. Representation of physics is improving, and computing capacity is increasing, but inevitable limitations will be present for the foreseeable future. The best avenue towards overcoming problems of spatial resolutions and understanding the regional detail of projected rainfall trends is to use a set of current generation GCM outputs as input to a downscaling method. Downscaling can be done either statistically or dynamically, and dynamical downscaling has several advantages over statistical downscaling, including the dynamical simulation of processes at finer-length scales and temporal scales (e.g. Cubasch et al. 1996). This study aims to produce climate projections of the regional detail of rainfall trend in Tasmania. Towards this goal, dynamical downscaling using an established regional climate model (RCM) was performed using the output from an established set of GCM simulations.

\subsection{Evaluation of model outputs}

Model performance must be critically evaluated before using their projections as a guide on likely climate changes with greenhouse warming. The critical evaluation of models is done at two levels: the component level and the system level. Component level assessment, or the evaluation of the components of models such as radiation scheme, clouds, water cycle and so on, adds to the confidence of the model as a whole, and helps identify problems hidden by model complexity (Meehl et al. 2007). An evaluation of the model at a system level is focused on the outputs of the full model through certain final output variables. Systems-level evaluation of models is done through model inter-comparisons and ensembles, calculation of metrics of model reliability, testing models against paleo-climates from the distant past and the testing of models against recent observations (Meehl et al. 2007).

This study aims to make projections of rainfall under plausible future scenarios of emissions. Therefore, simulations were produced using 'all forcings' given by established emissions scenarios, and no paleoclimate, attribution or control simulations were performed. Given this approach, the primary method of model evaluation is the comparison of model outputs of rainfall and rainfall processes to observations in the recent period. Another aspect of evaluation is also performed: the assessment of the drivers of rainfall trends against prior knowledge of climate dynamics, recent climate trends and previous model studies.

\section{METHODS AND RESULTS}

\subsection{Dynamical downscaling}

This study used dynamical downscaling of six simulations from the Coupled Model Intercomparison Project phase 3 (CMIP3) to a stretched grid global model that achieves a resolution of 0.1 -degree over the study site of Tasmania. The six GCMs used as input were CSIRO-Mk3.5, GFDL-CM2.0, GFDL-CM2.1, ECHAM5MPI/OM, UKMO-HadCM3 and MIROC3.2(medres), selected for their performance over the Australian region assessed by Smith and Chandler (2009). Downscaling was done using the regional climate model (RCM) named Conformal Cubic Atmospheric Model (CCAM) described in McGregor \& Dix (2008) in a 
Grose et al., Improving projections of rainfall trends through regional climate modelling and wide-ranging assessment

two-stage downscaling process for the period 1961-2100. Only daily sea surface temperature (SST) and sea ice concentration fields were used as the lower boundary condition to the first stage of downscaling run on a stretched global grid featuring $\sim 50 \mathrm{~km}$ resolution over Australia. Prior to the simulation, a monthly mean bias-adjustment was applied to the entire 140-year model SST dataset, calculated as the mean difference against Reynolds SST for 1961 to 1990 (Katzfey et al. 2009). This ensured that systematic differences between the GCM climates and the observed climate for this period were removed. The sea-ice distribution was not bias-adjusted. This could potentially lead to an inconsistency between adjusted SST and raw sea-ice, but this was investigated and shown not be an issue. SST and spectral nudging of the atmosphere were used as input to downscale from the intermediate grid to a grid with resolution of $\sim 10 \mathrm{~km}$ over Tasmania. Simulations were made under two SRES emissions scenarios: A2 and B1 (Nakićenović and Swart 2000). A full description of the downscaling methods used for this study is found in Corney et al. (2010).

The downscaled simulations show a finer resolution of the topography of Tasmania compared to GCMs (Figure 1). This is beneficial in simulating orographic rainfall processes at the regional scale. The regional detail of mean annual rainfall became more highly resolved through the stages of downscaling (Figure 2). The plots in Figure 2 show the multi-model mean, but each of the six simulations show a very similar mean pattern. The higher resolution simulations show a greater effect of orographic effects and therefore a greater differentiation of the higher rainfall in the west and the lower rainfall in the east, and also a secondary rainfall maximum in the mountainous northeast region.

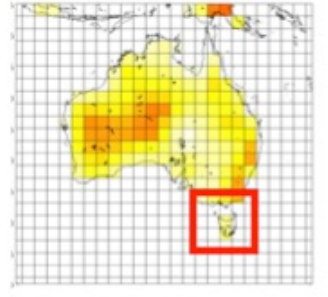

a.

b.

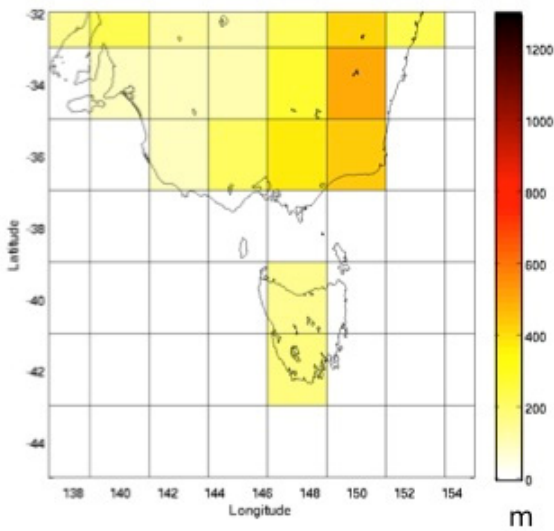

C.

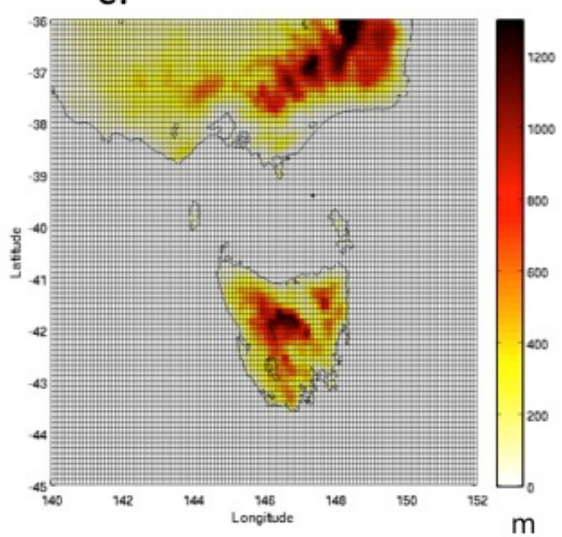

Figure 1. Maps of the study region showing the horizontal grid resolution and topography (m) represented in the different model resolutions, a) map of the Australian region showing a typical GCM resolution (GFDL 2.0 shown) and the location of Tasmania, b) as for (a) but zoomed on the study site of Tasmania, and c) the Tasmanian region showing the RCM grid resolution (CCAM, 0.1 degree grid)

a.

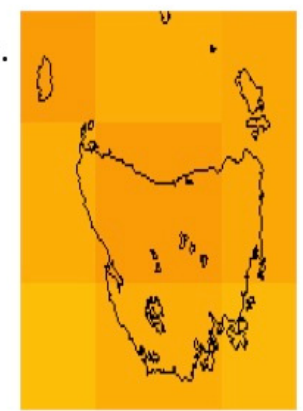

b.

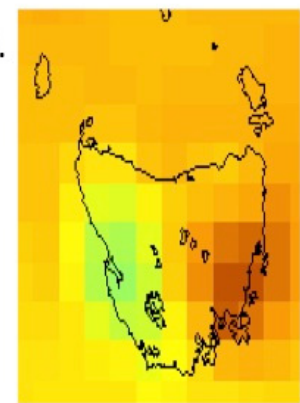

c.

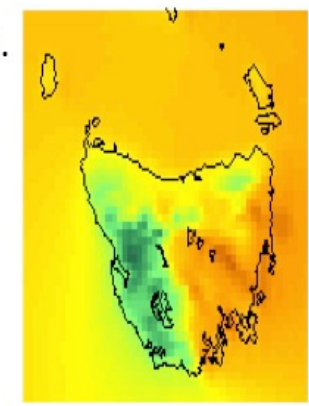

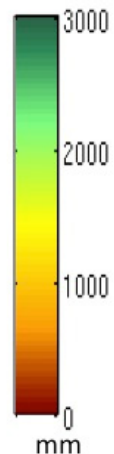

Figure 2. Mean annual rainfall total for the recent period 1961-2007 in the six-model-mean of the different resolution models, a) model mean of the six GCMs used as input in this study, b) the 0.5-degree resolution RCM simulations and c) the 0.1 -degree resolution RCM simulations 
Grose et al., Improving projections of rainfall trends through regional climate modelling and wide-ranging assessment

\section{ASSESSMENT OF MODEL OUTPUTS}

The primary method of model assessment was the comparison of model outputs to recent observed climate (in this case 1961-2007). Two different comparisons were made: a comparison of rainfall mean and variability as they are simulated in the final outputs, and a comparison of atmospheric fields to NCEP Reanalysis (Kalnay et al. 1996). A third element of evaluation and assessment of the simulations was made: examining the drivers of projected rainfall trends, and evaluating this against our understanding of climate dynamics, current observations and other model simulations.

\subsection{Comparison to observed rainfall}

Rainfall simulated by the RCM was compared directly to the daily gridded rainfall climate dataset made for the Australian Water Availability Project (AWAP, Jones et al. 2009). AWAP daily rainfall grids were interpolated to the same spatial resolution as model outputs to be directly comparable $\left(0.1^{\circ}\right.$ lat/lon grid). A large suite of comparisons was performed for each simulation for many different rainfall metrics. Examples comparisons (Fig. 3) of the mean annual rainfall total, the seasonal cycle of rainfall in broad districts and the count of days in different rainfall classes in winter are shown for the six-model ensemble mean. The results from each of the six model simulations are very similar. Clearly there is some range of values around the ensemble mean field, however analysis of this range (not shown) shows it to be relatively narrow compared to the overall climate. These comparisons are generally very favourable, indicating much higher spatial correlations with gridded climate data than the host GCMs (quantitative analysis in Corney et al. 2010).

AWAP
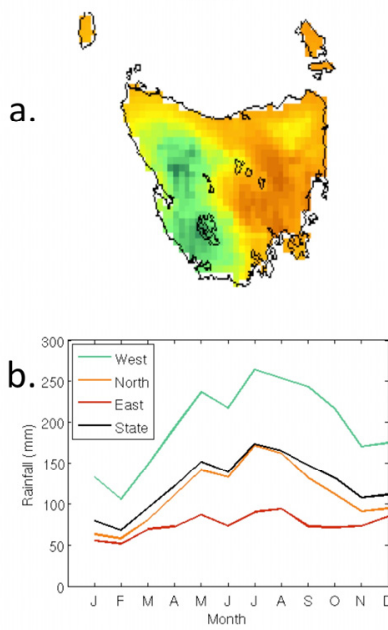

C.<smiles>C1CC2CC[C+]12</smiles>

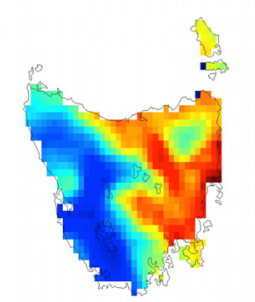

d.

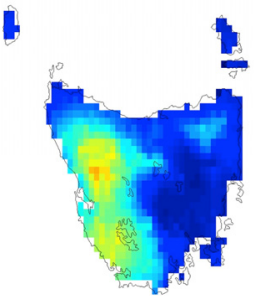

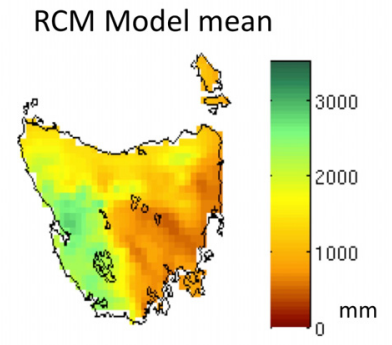

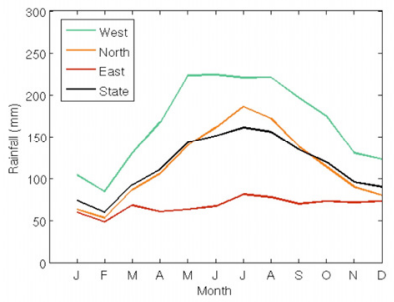

B.

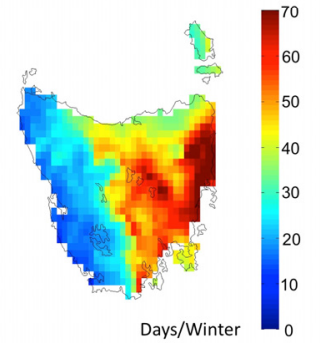

1

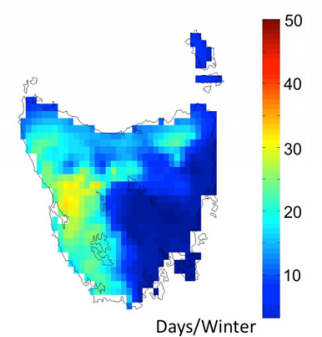

Figure 3. Rainfall characteristics in the mean of six GCMs downscaled using to 0.1-degree resolution using CCAM compared to AWAP gridded rainfall dataset for the period 1961-2007, a) mean annual rainfall, b) rainfall seasonal cycle for different zones, c) the number of no-rain days per winter, $\mathrm{d}$ ) the number of days with $>15 \mathrm{~mm}$ of rainfall per winter 
Grose et al., Improving projections of rainfall trends through regional climate modelling and wide-ranging assessment

\subsection{Atmospheric fields in current climate}

Increased atmospheric resolution improves the simulation of some aspects of the atmospheric fields relevant to rainfall processes. However, some biases in the mean state are not improved through increased resolution, including those associated with inadequate atmospheric physics or ocean biases from the GCM. An assessment of the simulation of some key atmospheric fields and indices can give context for assessing the reliability of the rainfall simulation.

Assessments of the RCM simulations of atmospheric fields compared with NCEP Reanalysis (Grose et al. 2010, Grose et al. In review) included mean sea level pressure, near-surface winds, the split-jet structure over eastern Australia and the strength and the position of the subtropical ridge. Also, an assessment was done of some of the most relevant remote drivers of rainfall variability such as atmospheric blocking and the Southern Annular Mode.

Fig. 4 shows the six-model ensemble mean $850 \mathrm{hPa}$ zonal wind fields over the region compared to NCEP Reanalysis 1 . Each of the six simulations appears very similar to this model mean, and would be virtually indistinguishable on this scale, so only the model mean is shown here. Visible on this plot is the mean position and strength of the mid-latitude westerlies that have a strong influence on rainfall in the west of Tasmania. A visual comparison of the plots shows that the RCM simulation matches NCEP Reanalysis in broad spatial pattern and strength. However, there is a mean northward and strong bias of the westerly belt, especially visible at the longitude of New Zealand. The spatial pattern of this circulation bias over the Tasman Sea region is also related to bias in the simulation of the split-jet structure and incidence of atmospheric blocking.

Being aware of the strengths and the remaining biases in the simulation of atmospheric fields in the current climate informs the interpretation and use of the simulations. This assessment can be used to qualitatively gauge confidence in the climate projections of rainfall trends. Aspects of rainfall mean and variability that depend on a process that is simulated well can be presented and considered with more confidence than rainfall trends that depend on processes that are more poorly simulated. For the examples shown here (Figure 4), the mean position and strength of the mid-latitude westerlies is reasonably well simulated in summer, so rainfall processes that rely on this can be viewed with confidence. However there is more doubt in the rainfall trends that will relay on the accurate simulation of winter-time split-jet structure and atmospheric blocking.
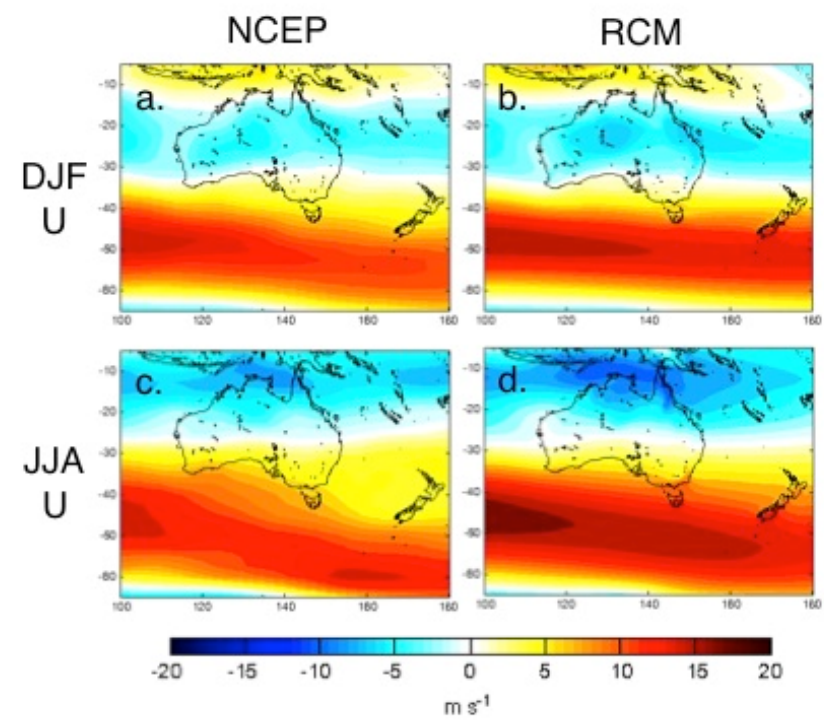

Figure 4. The mean $850 \mathrm{hPa}$ wind field during 1961-1990 in: a) austral summer (DJF) in NCEP Reanalysis, b) austral summer in the model mean of six RCM simulations ( $\sim 50 \mathrm{~km}$ resolution), c) austral winter (JJA) in NCEP Reanalysis, and d) austral winter in the model mean of six RCM simulations

\subsection{Drivers of future trends}

The third aspect of assessing the model simulations of rainfall by the RCM is through a critical analysis of the projected trend in rainfall mean and variability, and the key influences behind those projected trends. The goal of this analysis is to identify and understand the key drivers of rainfall trends and to check these against 
Grose et al., Improving projections of rainfall trends through regional climate modelling and wide-ranging assessment

our knowledge of climate dynamics, recent climate trends in those drivers and previous model studies. There is greater confidence in a rainfall trend if it is driven by a change that is very consistent with our knowledge of climate dynamics, the trend in that driver represents a continuation of recent trend that is likely to be due to climate warming (rather than natural variation) and is consistent with prior model studies.

Rainfall changes in Tasmania over the $21^{\text {st }}$ century simulated under the A2 emissions scenario are calculated as the difference in mean rainfall between 1980-1999 and 2080-2099. We are interested in comparing the multi-model mean trend or 'best estimate' from the RCM to the equivalent in the GCM, so the multi-model mean of each is shown here. The projected rainfall trends are quite different between summer and winter (Fig. 5). There are quite distinct differences in pattern between the GCMs used as input and in the outputs from each stage of downscaling. Taking summer (DJF) as an example, the GCM shows a trend for reduced rainfall across Tasmania (Fig. 5a), consistent with the general summer drying of the mid-latitudes (Meehl et al. 2007). However, the $0.5^{\circ}$ resolution RCM shows a region of increasing mean rainfall to the northeast of Tasmania that includes the small islands in this area and the northeast part of the main island (Fig. 5b). The $0.1^{\circ} \mathrm{RCM}$ simulation shows a more finely resolved image of the boundary, showing that the strongest increase in rainfall restricted to the coastal margin (Fig. 5c). The drying trend is still present for the west coast and Central Highlands regions in both RCM simulations.
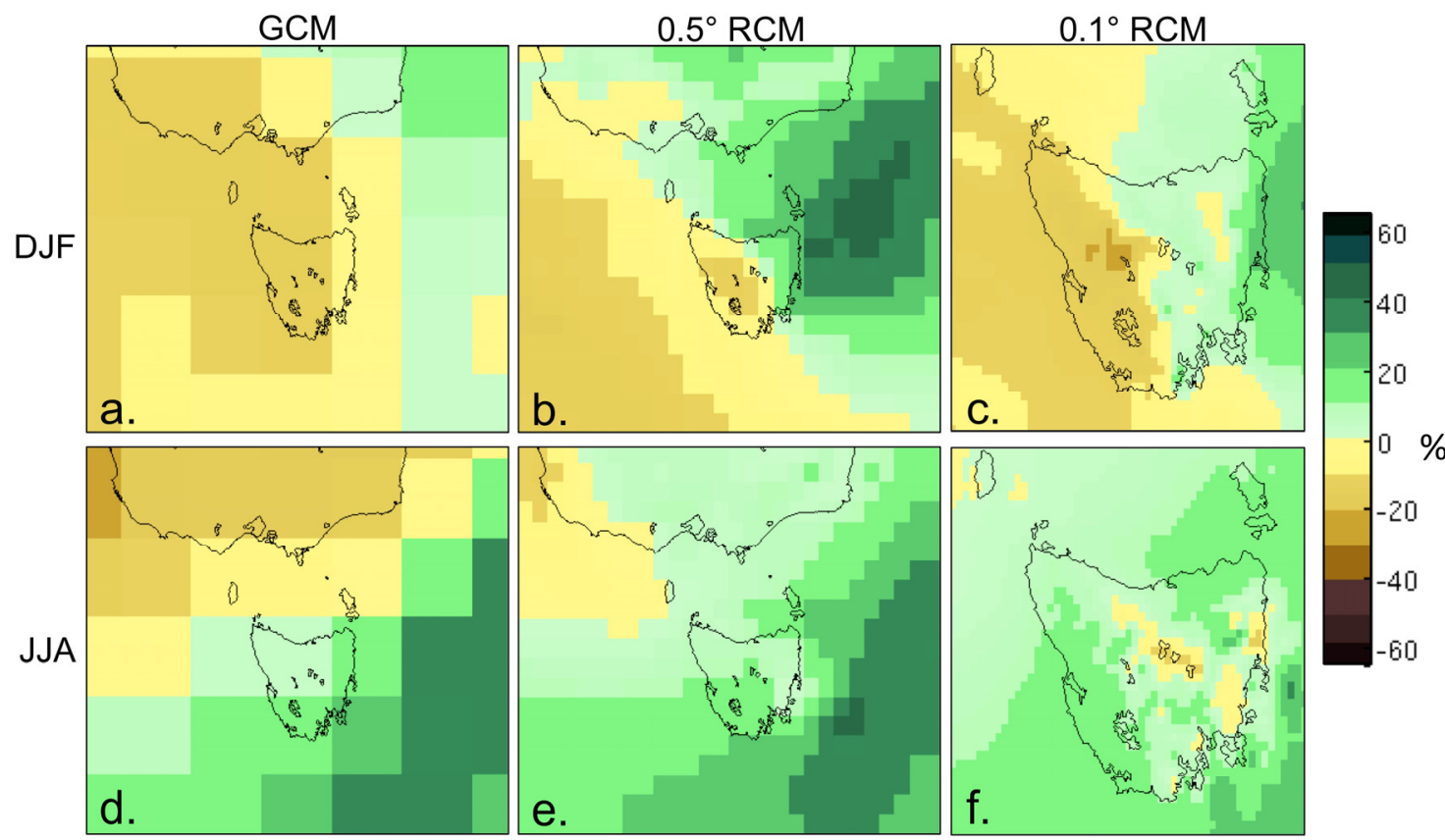

Figure 5. Rainfall change between 1980-1999 and 2070-2099 in the six-model mean of the simulations examined in this study under the SRES A2 emissions scenario for austral summer (DJF) and austral winter (JJA), a) in summer from the original GCMs used as input, b) summer from the $0.5^{\circ} \mathrm{RCM}$, and c) in summer from the $0.1^{\circ} \mathrm{RCM}$, d-f) as for a-c but in winter

The three key questions regarding these projected rainfall changes for this aspect of evaluation are:

1. What is the driver behind these trends?

2. Is the change in this driver plausible?

3. Is the change more realistic in the RCM compared to the GCM?

For the example of summer rainfall, the driver behind the rainfall trends in the western region and the eastern region can be examined separately. A general shift in the mid-latitude westerlies, accompanied by a southward movement and strengthening of the subtropical ridge and an increase in the high phase of the SAM are consistent with the decline in rainfall in the western district, similar to much of the mid-latitudes. This is consistent with general theory and GCM studies, and is not considerably different in the RCM simulations. The increase in rainfall on the east coast however is different from the GCM simulation and appears to be due to processes that are less well simulated at the lower resolution of GCMs. The rainfall increase is coincident with an increase in SST in the same region, caused by a strengthening of the East Australia Current (Grose et al. 2010). This extension is consistent with recent observed trends attributed to 
Grose et al., Improving projections of rainfall trends through regional climate modelling and wide-ranging assessment

climate warming (e.g. Hill et al. 2008), and is found to some extent in all climate model simulations. The atmospheric response to this warm current appears to be better captured in the RCM compared to the GCM, and includes increases in onshore moisture flux, atmospheric instability indicated by convective potential energy (CAPE) index and increases in the fraction of convective rainfall in northeast Tasmania and in the nearby waters. The area of increased rainfall is also consistent with an increase in atmospheric blocking in summer (Grose et al. In Review) that would lead to a corresponding increase in incidence of onshore easterly winds.

\section{CONCLUSIONS}

The result of dynamical downscaling and assessment is a fine resolution projection of rainfall, a greater understanding of the strengths and weaknesses in the model in simulating rainfall, and an understanding of what is projected to drive the rainfall changes. Together, these factors strengthen our confidence in the rainfall projection for Tasmania. This confidence is derived from the inclusion of additional information through the downscaling process (such as increased topography of Tasmania and the atmospheric response to changes in SST), which leads to higher levels of skill when compared with the observed climate in the downscaled simulations. In this way, careful downscaling increases the skill of the simulations and gives a more detailed projection of the effect of greenhouse warming on the local climate in terms of the knowledge of the current climate.

\section{ACKNOWLEDGMENTS}

This work was supported by the Australian government's Cooperative Research Centre Program through the Antarctic Climate and Ecosystems Cooperative Research Centre (ACE CRC). Climate Futures for Tasmania (www.acecrc.org.au/Research/Climate Futures) was possible with support through funding and research of a consortium of state and national partners.

\section{REFERENCES}

Corney, S.P., J.K. Katzfey, J.L. McGregor, M.R. Grose, J. Bennett, et al. (2010). Climate Futures for Tasmania: climate modelling. Hobart, Tasmania, Antarctic Climate and Ecosystems Cooperative Research Centre.

Grose, M.R, I Barnes-Keoghan, S.P. Corney, C.J. White, G.K. Holz et al. (2010) Climate Futures for Tasmania: General climate impacts. Hobart, Tasmania, Antarctic Climate and Ecosystems Cooperative Research Centre.

Grose M.R., M.J. Pook, P.C. McIntosh, J.S. Risbey, N.L. Bindoff, (In Review). The simulation of cutoff lows in regional climate models: reliability and projected trends. Climate Dynamics

Hill, K.L, S.R Rintoul, R Coleman, K.R and Ridgway, (2008). Wind forced low frequency variability of the East Australia Current. Geophysical Research Letters 35, L08602, doi:10.1029/2007GL032912

Jones, D.A., W. Wang and R. Fawcett (2009). High-quality spatial climate data-sets for Australia. Australian Meteorological and Oceanographic Journal 58: 233-248.

Kalnay, E., M. Kanamitsu, R. Kistler, W. Collins, D. Deaven, et al. (1996). The NCEP/NCAR 40-year reanalysis project. Bulletin of the American Meteorological Society 77: 437-471.

Katzfey J.J, J.L McGregor, K.C Nguyen, M.J Thatcher. 2009. Dynamical downscaling techniques: Impacts on regional climate change signals. In: Anderssen RS, Braddock RD, Newham LTH (eds). 18th World IMACS Congress and MODSIM09 International Congress on Modelling and Simulation, Modelling and Simulation Society of Australia and New Zealand and International Association for Mathematics and Computers in Simulation, July 2009. pp. 2377-2383.

McGregor, J.L. and M.R. Dix (2008). An updated description of the conformal-cubic atmospheric model. High Resolution Simulation of the Atmosphere and Ocean. K. Hamilton and W. Ohfuchi, Springer: 51-76.

Meehl, G.A., T.F. Stocker, W.D. Collins, P. Friedlingstein, A.T. Gaye, et al. (2007). Global Climate Projections. In: Climate Change 2007: The Physical Science Basis. Contribution of Working Group I to the Fourth Assessment Report of the Intergovernmental Panel on Climate Change. S. Solomon, D. Qin, M. Manning et al. Cambridge, United Kingdom, Cambridge University Press.

Nakicenovic, N., J. Alcamo, G. Davis, B. de Vries, J. Fenhann, et al. (2000). Special Report on Emissions Scenarios. A Special Report of Working Group III of the Intergovernmental Panel on Climate Change. Cambridge, United Kingdom, Cambridge University Press.

Smith, I. and E. Chandler (2009). Refining rainfall projections for the Murray Darling Basin of south-east Australiathe effect of sampling model results based on performance. Climatic Change 102(3): 377-393. 